\title{
South African music learners and psychological trauma: educational solutions to a societal dilemma
}

\author{
I SWART $T^{l}$
}

\begin{abstract}
Emotional trauma affects a large proportion of the South African population. This article addresses its influence on music learners, including its effects on brain development, relational development, learning and music-making. The power of the educator to reshape a child's brain by providing a nurturing and consistent environment is stressed. The effect of the environment in modulating epigenetic expression is discussed in conjunction with object relations theory as a model for human relations. Brain-damaging consequences of early attachment trauma can be reversed by healing these patterns through the educational system. Music teachers' observations of how trauma influenced their students' music-making, emotional expression, memory and relational patterns, students' observed recoveries from trauma, and the influence of teachers' own experiences on their appraisal of students' experiences are discussed. The article also examines the advice of healthcare professionals to teachers and the latter's legal responsibilities in terms of the reporting of abuse. This is done with reference to responsibilities regarding witnessing and referring, and the possibility of empowering learners through unlearning helplessness and fear. Treatment strategies discussed include pharmacological intervention, psychotherapeutic intervention such as CognitiveBehavioural Therapy, hypnosis, Eye Movement Integration Therapy and Somatic Experiencing. Music can serve as an object relationship representing human experience, expressing the movement of feelings, bypassing the cortical function and expressing what words cannot. It can aid in repairing damaged communication processes and restore the sense of bodily connectedness. Suggested future directions include the incorporation of teaching modules on educational psychology in music teachers' training curricula, providing support for students, reducing the risk of secondary traumatisation to professionals, and transdisciplinary collaboration.
\end{abstract}

Keywords: Brain development, educators, epigenetic expression, integration, previously disadvantaged, trauma

Disciplines: Education, music education, psychology, sociology

\section{Introduction}

\section{Trauma in our society}

In a society plagued by violence, poverty, political inequality and broken homes, the effects of trauma $^{2}$ are familiar to most. For the purposes of this article, Corsini's definition of trauma as the result of a painful event is appropriate. He defines trauma as follows:

Dr Inette Swart is a post-doctoral fellow at the School of Music, North-West University, Potchefstroom Campus. Contact details: Inette.Swart@nwu.ac.za

This article builds on previous work done for the DMus degree at the University of Pretoria under the guidance of Prof. Caroline van Niekerk and Dr Woltemade Hartman (Swart 2010). Some material from this unpublished thesis was incorporated into the current article. 
The result of a painful event, physical or mental, causing immediate damage to the body or shock to the mind. Psychological traumas include emotional shocks that have an enduring effect on the personality, such as rejection, divorce, combat experiences, civilian catastrophes, and racial or religious discrimination (Corsini 2002, 1019).

A subtle distinction is made between trauma, as defined above, and a 'traumatic event or experience', which Corsini $(2002,1019)$ defines as physical or psychic injury that is stressful or shocking and that may be the original cause of an emotional or mental disorder. It is important that teachers take note of his contention that some such events taking place early in life could form the foundation for subsequent neuroses or psychosis. If the impact of trauma can be dissolved during the foundational years, we could make progress in solving a major societal problem.

This article focuses on what can be done for the younger members of society to break this cycle of suffering. It is important to be aware that the consequences of trauma could be transmitted from one generation to the next (Yehuda et al., 1997; Heart, 2005; Maviglia, 2006). The new generation of South African musicians might still be dealing with the burden of the apartheid legacy because of the experiences of their parents and grandparents, their economic circumstances or lack of educational opportunities. Therefore teachers should be sensitive to the psychic disposition of 'previously disadvantaged' music students. ${ }^{3}$

In his autobiography, Long Walk to Freedom, Mandela (1994, 751) writes:

'The oppressed and the oppressor alike are robbed of their humanity... For to be free is not merely to cast off one's chains, but to live in a way that respects and enhances the freedom of others.'

This underlines how not only a part of the South African population, but all races share the burden. Neither the abused nor the abuser escapes unscathed, while without understanding, insight and forgiveness, people who were abused might become abusers themselves (Van der Kolk 1989). Whilst warning that real reconciliation could only occur on the basis of the truth, Tutu $(2011,47)$ states that a future without forgiveness is inconceivable, for 'revenge merely begets further violence, causing an inexorable spiral of reprisal...'.

In order to properly describe trauma as understood by the most recent research, which tends to emphasise the importance of cumulative small traumas, additional factors need to be highlighted. According to Levine (1997, 128-129), the factor that determines whether an event could be classified as traumatic for a person is whether its impact remains unresolved. The perception of the nature of an event by an individual determines whether trauma results. The terms 'perceived life-threatening experiences' and 'perceived overwhelming experiences' feature repeatedly in the literature (e.g. Levine 2005, 7; Van der Kolk \& McFarlane 1996, 6). For Levine (1997, 147), the 'core of the traumatic reaction' constitutes hyperarousal, constriction, dissociation, denial and feelings of helplessness. Scaer (2005), in formulating his hypothesis that the body bears the burden of adverse experience, explains at length the impact of many small cumulative traumas on the body and mind. In addition, Scaer $(2005,215)$ states that complex trauma is associated with sufferers of PTSD (Post-Traumatic Stress Disorder) who were subjected to many episodes of traumatic stress. Regarding cumulative trauma experienced by children, he $(2005,262)$ states that multiple events and forms of trauma experienced in childhood lead to complex trauma, and he specifies the associated 
syndromes to be conversion, somatisation, dissociation, borderline and narcissistic personality disorders.

The purpose of this article is to explore music teachers' beliefs about and approaches to their students' stated or suspected traumatic experiences against the background of current trauma research, psychological theories and available knowledge about the functioning of the human brain. The article aims to raise awareness and empower teachers through, first, explaining theories on human development as well as the possible influence of trauma on development, and, secondly, drawing on relevant insights from reports by music teachers and advice from healthcare professionals (HPs). It shows that it is possible to mitigate the damaging effects of adverse experiences through establishing safe and secure educational environments, relationships and boundaries.

\section{Influence of trauma on the human brain}

Trauma affects not only the body, the emotions and the personality, but also the brain. The earlier the trauma, the more likely it is that damage to brain structures could result, as will be explicated more fully below on the basis of Scaer's $(2005,58)$ explanation of the effect of traumatic events. He states that in the brain of a trauma victim, the synapses, neurons and neurochemicals have been altered, consequently changing the perceptual experiences that constitute the mind. In Scaer's view, this confusion of time, together with a thwarted freeze discharge, further immobilises the trauma victim, since unresolved threat bombards procedural memory.

Overwhelming traumatic events cannot be fully and meaningfully processed by the human brain without proper intervention and assistance. As a result of the high level of arousal and elevation of stress hormones accompanying such events, traumatic memories can become more deeply engrained in neural pathways than ordinary memories (Roth \& Friedman 1998, 12). Therefore, although belonging to the past, a traumatic event could continue to have an influence on a learner and his or her development, relations, learning and music-making.

This article contends that music learners and their music-making could be influenced by traumatic experience, but that music can also be used in the treatment of trauma sequelae. Lathom-Radocy and Radocy $(1996,69)$ define music as 'a product of cognition and affect operating under particular psychological and physiological constraints'. Music experienced by an individual or group involves many factors, including psychological and social factors, which determine the nature of the experience for those involved. Music is sometimes used in the treatment of trauma victims (for example, see Lee 2009; Sutton 2002; Williams 1978). In addition, much has been written about music's beneficial effects on the brain (for example, see Rauscher, Shaw \& Ky 1993; Jausovec, Jausovec \& Gerlic 2006). Therefore, while it is clear that trauma can change the brain, the contention here is that music, which also has the ability to exert a strong influence on brain development, could be instrumental in the recovery process. Modification of relational patterns in educational settings - through an understanding of basic concepts in object relations and developmental theories consequently affecting the working of the brain, is explicated as the other dimension of the recovery process.

\section{Music as communication and relation}

The music teachers who described their observations of the impact of trauma on their students in the research questionnaire in Swart's study (2010), as well as additional 
unpublished research (2012), were primarily involved in teaching Western art music, or what is also commonly known as 'classical music'. The arguments could also be applicable to other forms of music, and some also to other educational environments.

At a basic level music can be defined as 'organised sound' (Levitin 2006, 111). Frawley (1997, 228) explains that sound can either reinforce or release emotion. Structuring and making meaning of abstract sound by organising it into melody, harmony and rhythm are part of the creative process utilised by composers and performers. In a music therapy setting, freely expressing emotion through sound, improvising, responding to cues from others and structuring experience can have therapeutic value where the communication process has been damaged, extending even to the treatment of mental disorders such as autism and schizophrenia (Sutton 2002, 25-32; Di Franco 1993, 83). Inclusive definitions of musicmaking include Elliott's description of what he calls 'musicing' as encompassing performing, improvising, composing, arranging and conducting (Elliott 1995, 49, 109), a definition in which 'teaching' is noticeably omitted. Holmgren (2008/9) defines music performance as 'an experience, encompassing teaching and learning, analysis and critique, and the combined experiences of those who interact in diverse ways with the processes and products of making music'. In line with Holmgren's view, this article focuses on the experiences of teaching and learning, regarding both as aspects of music-making.

The emphasis in this article is on 'relating' as a dynamic, ongoing interaction between human beings. In short, music is seen as a process of communicating with and relating to others. It is not only through the content that they teach, but also through the way in which they relate to learners that teachers exercise such a strong influence on their students. Watkins describes this relational aspect beautifully with a concept called 'resonance' $(2005,8)$ :

'Resonance is a wonderful skill, the ability to see the world, and even our own selves, through the eyes of another. By internalising perceptions of another, we invest our own self energy and turn "it" into "me". If resonance were more practised, parents would understand children, teachers would understand students, and nations would understand one another.'

Before an attempt can be made to understand music or art as representative or expressive of human experience, it is necessary to ask what music is for those involved with it. Welbel (2009) and Stein $(2007,444)$ explain that from a psychoanalytic or developmental point of view, the music and its auditor can be described as being in an object relationship. It may be deduced that the same psychic operatives are at work between performer and the instrument. Welbel explains that a relationship always exists between the artist and his/her surroundings, and adds that while psychoanalysis itself is sometimes dismissed, its principles are still applied by the way relationships are described. She even describes music as a substitute for the loved object that leaves and returns, and notes that this perception provides the possibility of mastering anxiety in some cases. In her view, music is the best way to re-enact trauma, while performance of music is therapy in itself - translating into performers getting therapy every day. It will be seen below how music's relational role can play an integral part in the healing process.

McClary (2007), Marshman (2003), Skar (2002) and Tilly (1977), all authors who discuss music's role in the treatment of trauma, follow the psychotherapeutic philosophy of Carl Jung. Central to Jung's psychology is the concept of individuation, the early developmental components of which are discussed in the section on Klein's adaptation of Freud's work into her 'object relation theory' of child development (Klein 1946). Jung believed that true works of art have their origin in the collective unconscious and could possibly bring balance to the 
conscious values of a society. The artistic impulse to create has similarities to a pathological state, but it is not entirely the same (Marshman 2003, 24, 26, 28). Despite all the biological explanations, the question can still be asked: On the continuum of past and present experience as well as future hopes, is it brain mechanisms that are responsible for behaviour and creativity, or is it deeper-lying inspirations, including philosophical constructs such as the collective unconscious, or both?

\section{Pervasive effects of early trauma}

\section{The effect of the environment on epigenetic expression}

While research has shown that trauma can damage the brain (Bremner 2002), very promising research on epigenetics offers hope that we might have more control over our destiny than was formerly believed. That is, provided we are able to modify our environment into a relatively nurturing and safe place. Epigenetics is defined as 'the study of heritable changes in gene expression that are not due to changes in DNA sequence' (Eccleston, DeWitt, Gunter, Marte, \& Nath 2007). Cloud (2010) explains that gene expression governed by the epigenome sits on top of the genome and can tell genes to switch on or off, allowing the expression of the genome to be modified by environmental factors such as diet, stress, nurturing and prenatal nutrition. It works on two basic principles: methyl groups attaching to genes, called DNA methylation, turning genes on or off (Cloud 2010), and the utilisation of coiling proteins which, by wrapping DNA into spools, can hide genes by tightening them or allowing them to become active by relaxing spools (Zimmer 2010). This mechanism changes the way brain cells work and has implications for relieving people of psychiatric disorders through rearranging the pattern of gene expression by modifying the environment (Zimmer 2010).

The ground-breaking study on the influence of environment on epigenetic expression was conducted by Weaver, Cervoni, Champagne, D'Alessio, Sharma, Seckl, Dymov, Szyf and Meaney (2004). They found that rat pups from mothers who groomed and licked them a lot grew up to be calm adults, while pups from mothers who seemed to ignore their pups became anxious adults. In addition, by taking rats from the different groups and placing them with foster mothers with the opposite relational pattern, they proved that whether a rat pup grows up as anxious or relaxed depends on the mother that raises it and not the mother that gave birth to it, showing that nurturing can bypass the slow processes of random mutation and natural selection (Genetic Science Learning Centre 2012).

Child abuse may leave its mark on victims in a similar manner by altering epigenetic marks in the hippocampus ${ }^{4}$ and as a result making fewer stress receptors on the neurons, leaving victims unable to regulate their stress hormones, which in turn leads to anxiety (Zimmer 2010). Zimmer (2010) concludes that differences between personalities are determined not only by genes, but that love also plays a major role in shaping personalities. Therefore, the hope for traumatised children lies in the environment being modified by caring others, such as family or teachers, into a nurturing and safe place as opposed to a dangerous, cold and unpredictable place.

4 The hippocampus is a brain structure responsible for the assimilation of incoming stimuli into meaningful material which can be stored in memory (Spiegel 2008). 


\section{Further biological effects of trauma and its implications for therapeutic intervention}

Understanding the effects of trauma on the brain is central to understanding its pervasive influence. Trauma research veteran and expert in mind-body healing, stress and selfregulation, Robert Levine (2010, 249), asserts that we cannot escape the fact that we are bound by the brain's control over, influence and operation on our bodies. Levine $(2010,249)$ states: 'To know ourselves is to know our brains, and to know our brains is to know ourselves - more or less'. According to Levine (2010, 254), our higher thought processes are servants rather than masters, as can be illustrated by the fact that language alone is not sufficient to soothe a small child, but needs to be accompanied by holding, rocking and gentle sounds. He states that words need to have a physical context for them to be healing (Levine 2010, 264). An important aspect of the symptoms traumatised people exhibit is the immediacy of their emotional reactivity. This could cause them to overreact and intimidate others (Van der Kolk \& Saporta 1991, 202) and is connected to the observation that under stress these people may feel as if they were traumatised again (Van der Kolk 1996, 291).

Levine's work (for example 1997, 99-100) emphasises the role of instinctual responses, the 'thwarted freeze response', the release of 'frozen energy' and the use of physical contact (Levine 2010, 3-9) in the quest for healing. Interventions such as talk therapy and CognitiveBehavioural therapy do not fully address these aspects, since they both emphasise the higher thought processes and verbal accounts of events without addressing somatic components. Levine $(2005,27)$ explains that the instinctual parts of both human and animal brains are almost identical, while it is the rational part of our brain (the neo-cortex) which is uniquely human. Our first responses to shock and trauma are instinctive, while rational appraisal and reflection follow only later. Therefore, as Levine shows, the challenge in treatment is to address the primary instinctual responses and memories of threat. He states that 'successful healing methods inevitably involve establishing a connection to the body' $(2005,28)$.

Recent developments in the field of neuropsychology increasingly acknowledge biological changes caused by trauma as a causative factor in the symptoms characterising its aftermath. Van der Kolk and Saporta $(1991,199)$ use the term 'physioneurosis' to describe this phenomenon. While Scaer $(2005,58)$ refers to the relationship between changes in the brain of the trauma victim and alteration of perceptual experience, Nijenhuis, Van der Hart and Steele (2004) link trauma-induced neurobiological changes to difficulties with integrative functions.

Physical brain structures can also be affected. Unfortunately, the scope for research into this very promising aspect in furthering our understanding of the effects of trauma is mostly limited to post-mortem findings. Numerous authors refer to decreases in hippocampal volume associated with trauma and especially with complex trauma (e.g. Scaer 2005, 75; Bremner 2002, 60-2; Robertson 1999, 236). Spiegel (2008) states that a smaller hippocampus would likely have a limiting influence on a person's capacity to encode, store and retrieve memories and to manage associated emotions.

The lack of unconditional love is another aspect of unresolved trauma that should be referred to. As was illustrated above, love and nurturing affect us not only emotionally but also physiologically. The emotional trauma inflicted upon a child who does not receive unconditional love can, according to Miller (1997) and Weeks (2000), result in such a child not developing an inner sense of self. Weeks argues that children and even adults traumatised in this way are frequently encountered among high-achieving musicians. Miller $(1997,1)$ writes that emotional discovery about the history of our childhood is the only enduring 
weapon to combat mental illness. Although the truth of the influence of early experience cannot be denied, in reality we are continually confronted whilst going through life with situations which have the potential to modify our 'established' physiology. This article maintains that, whilst re-traumatisation remains a dangerous possibility that should never be left out of consideration, subsequent positive encounters can erase or change the markers of trauma on our biology. On the other hand, treatment strategies that overemphasise revisiting past events can perhaps diminish the capacity for taking control over current circumstances, the capacity for making choices and responding to challenges, as well as overlooking serendipitous opportunities for healing on the path through life.

\section{Insights from the theory of object relations into personality development}

Much can be understood about our ways of relating to others through a basic comprehension of object relations theory. Such knowledge could prove particularly valuable to teachers observing the behaviour of learners. Object relations theory holds that the way infants experience their parents shape the way in which they subsequently relate to other people and situations (St. Clair 2000). For the young child the primary caregivers play the biggest role in shaping their experience of the world as a safe or unsafe place, as well as influencing the brain circuits which determine their most likely behaviour and responses in future relationships. This article contends that, in the light of the epigenetic research referred to above, these behaviours and responses can be modified later in life; this approach therefore goes beyond the more deterministic conclusions reached by biological theorists such as Schore (2010), referred to below.

'Object relations', a term coined by Ronald Fairbairn, is a developmental theory developed by Mélanie Klein through her observations and work with children. Building on the work of Sigmund Freud, Klein elaborated on the significance of early developmental phenomena by focusing on pre-oedipal development with object seeking (primarily the mother or the breast) rather than drive satisfaction as the primary motivation (St. Clair 2000). The infant's unconscious 'phantasy' is tested against experience of reality; introjections of the 'good object' help the ego to defend itself against anxiety, while projection of undesirable qualities is an attempt to eject the bad (Segal 1981). Early in its development, the child can only perceive experience as all good or all bad, characterising the 'paranoid-schizoid position' by splitting or part object relations'. Since the ego tends towards integration, splitting is never fully effective and it is during the 'depressive position' that others are now perceived as whole, integrating 'good' and 'bad' characteristics (Klein 1946).

In the light of the above, it follows that traumatic early attachment can form dysfunctional patterns and challenge the child in forming and sustaining healthy relationships with others. Levine $(2005,71)$ explains that, if those who are supposed to love and protect us instead turn out to hurt and violate us, a double bind is created. This can be explained as follows: unlike children from secure families who are able to go to adult sources of protection and develop trust and a sense of safety in the world, children who are abused are compromised in their ability to develop a sense of safety and stability, and their basic sense of self and trust is undermined, causing them to carry thwarted survival patterns into adulthood (Levine 2005). This forms the origins of relational difficulties as well as self-esteem issues, and often prevents people from reaching their full potential (Levine 2005). If modified early in the child's development through the educational system, these maladaptive patterns can be changed. According to Schore (2010), neural circuitry of the stress system is located in the early developing right brain. He postulates that traumatic attachments occurring at a critical 
period of development will lead to dysfunction during stress and predispose individuals to Post-Traumatic Stress Disorder (PTSD).

Schore (2010) states that the 'good-enough mother' of a securely attached infant responds appropriately to his/her emotional expressions and permits the child access after separation, thereby expanding the child's coping capacities. The developmental attainment of such an efficient internal system serves the function of regulating arousal and psychobiological states and allows for affect, cognition and behaviour to evolve. An inaccessible caretaker responding to her infant's expressions of emotion and stress with rejection induces extreme, enduring states of arousal and stimulation in the infant. The child feels its survival is at risk, its capacity to trust is jeopardised and until these internal states are brought under control, the child can 'do nothing else' and fails to develop (Schore 2010). Schore states that, while the organisation of the brain's coping mechanisms occur during certain critical periods, these systems are also most plastic during those times and can be modified by infant mental health interventions aimed at altering the affect-communicating capacities of high-risk mother-infant dyads and altering the intergenerational transmission of PTSD. He does not state what the alternatives are if these critical periods in development have been passed and intervention takes place at a later age.

\section{Nature of the music teaching relationship}

What distinguishes the teacher-student relationship in music education from that in general education is the often individual or small-group nature of lessons. Teachers know their students on a personal level and often have a major influence on their lives. They should know that they are not therapists and cannot act in that capacity. However, the importance of their influence on their students should never be underestimated. Welbel (2009) explains that ultimately any relationship between human beings can have therapeutic components, but even more so the relationship between a teacher and a student. She goes as far as stating that teachers are therapists nolens volens - whether they want to be or not. Howard Gardner, developer of the theory of 'multiple intelligences', is reported to have said that '[t] he teacher ... must be at once physiologist and psychologist' (cited in Brice 2004, 41)

The responsibility that teachers have for the wellbeing and musical maturation of their students extends to choosing age-appropriate music for them to learn. Welbel (2009) said in a personal interview that young children should not play too dramatic music, since they then 'take the trauma of the composer on their own soul'. Such music could include mature compositions or music written during times when composers were experiencing great individual or collective turmoil. Excessively virtuosic music written for themselves by young composers embarking on solo careers could also fall in this category. Types of compositions given to students to play have certainly become a concern recently as younger and younger musicians competing in contests are playing increasingly demanding music - both technically and interpretatively. Sometimes their life experience does not yet prepare them for this, but it could also be possible that children who had suffered trauma could be inclined to play more mature music. Skar $(2002,631)$ observed that adult students' attraction to certain types of music could reveal dormant aspects of the unconscious. If taken to possibly apply to younger students as well, this suggests that giving them the freedom to indicate their own musical preferences could facilitate natural intra-psychic processes of finding equilibrium. Stein (2007, 451) cautions about the very delicate balance that exists between different possibilities: art can represent experiences that could otherwise be too overwhelming to express, but it can also break down the necessary protective mechanisms that trauma victims employ to suppress 
extreme experience. Identifying emotions appropriate to the music and guiding students to assimilate the development of these emotions into the musical structure - for instance how the musical ideas and intent transform during the course of a work, such as through the exposition, development and recapitulation sections or a series of variations - is simply music therapy in a different form (Welbel 2009).

\section{Research methodology}

\section{Introduction: holistic research of a qualitative nature}

The experience of trauma is very common. Still, victims often feel isolated before they discover, through therapy or the sharing of their experiences, that they do not have to suffer alone. Research such as exemplified by this study can play a role in giving a voice to the young victims of trauma through the observations of those who work with them, as well as providing knowledge to those interacting with and educating them. Ashworth $(2003,24)$ confirms that it is usually only qualitative research that properly takes into account the diverse experiences of individuals and that can make the voices of the excluded heard. Personal interpretative viewpoints are integral to qualitative research, and the article presents the experiences and opinions of the respondents. Welbel (2009) reminds us that psychology is an art form and not only a strictly scientific endeavour. In fact, this article aims to combine the scientific and artistic attitudes. Hanser's (1999, 52) description of music therapy as 'combining the best of art and science in the service of helping others' is appropriate for this article, which investigates phenomena in music and psychology in order to find ways to ease the pain and suffering caused by traumatic stress.

This article examines not only the reactions and responses of music learners to trauma, but also the role that educators can play in softening and even reversing the impact of unfortunate experiences. The literature on trauma, brain development and object relations explains the mechanisms of development which, when thwarted, produce pathological manifestations. It is hypothesised that the pathway to resolution can lie in the modification of pathological patterns, both relational and neuronal, through the educational system.

\section{Research method}

After reviewing the available literature on trauma, psychotherapeutic intervention strategies, and the use of music by professionals working with individuals recovering from trauma, I decided on an open-ended qualitative questionnaire as a means of data collection. Two questionnaires were formulated, one for music teachers who have worked with traumatised students and the other for prominent healthcare professionals (HPs) who indicated that they have worked with musicians affected by trauma. Responses were obtained from 27 music teachers and 17 health-care professionals including psychiatrists, psychologists, occupational therapists, physiotherapists, speech-language pathologists and counsellors (Swart 2010). Selected aspects of the research results from Swart (2010) on the influence of trauma on musicians, as well as additional unpublished data gathered by the same methods (Swart 2012), are incorporated. The feedback was from music teachers and HPs who, although some had lived and studied elsewhere previously, were working within the South African music environment at the time they responded to the survey. 
Data extracted from the research results for the purposes of this article related to the way that learners responded to trauma as evident in their relationship to music, their instrument or voice, and their teachers, as well as general signs and effects of trauma observed by teachers. The influence of teachers' own experiences on their appraisal of the experiences of their students is briefly referred to; these data were obtained from the final question of the teachers' questionnaire, namely a section marked 'optional', inviting them to provide brief introspective self-reports of traumas experienced by teachers themselves and treatments received, if any. Teachers were asked whether they had referred students for treatment, and if they observed improvement in students they knew were receiving treatment. The HPs' observations of common mistakes made by teachers in dealing with traumatised learners and their advice to teachers were selected from the feedback.

\section{Limitations}

The exploratory nature of the research relies on individuals' own interpretations of their experiences, as well as their observations of the experiences of others, namely those of students and clients or patients. These are subjective evaluations that cannot be reliably quantified. It is not the aim of this article to provide any predictions about how music learners might respond in dealing with traumatic circumstances, but rather to increase awareness, including awareness of appropriate professional ways of handling such situations that may arise. The article can only provide knowledge to broaden educators' frame of reference: it cannot provide recipes on how to apply such knowledge.

A limitation of non-experimental research designs noted by Marczyk, De Matteo, and Festinger $(2005,147)$ is that, since no control is exerted over the variables and environments being studied, extraneous variables as the cause of observed phenomena and effects cannot be ruled out.

\section{Response to the research questionnaire: opinions of participant music teachers}

\section{Population of respondents}

Twenty-seven music teachers responded to the questionnaire (Swart 2010, 2012). For the purposes of this article, research results were greatly condensed and only points relevant to the current topic extracted. The population of respondents included teachers of voice, piano, organ, violin, cello, classical guitar, transverse flute, recorder, clarinet, saxophone and trumpet. Years of experience in music teaching ranged from 6 to 51 years, with the majority of respondents having 30 or more years of experience. The levels taught ranged from beginners to concert artists, with most respondents having a balanced experience of teaching at different levels as well as teaching students from previously disadvantaged communities.

Kinds of trauma reported are abuse of various perpetrators including that by students' parents; verbal, sexual and physical abuse; dysfunctional family set-ups; the breaking up of families and divorce of parents; being raised by a single parent; the onset of mental illness; death of a parent, relative or friend; suicide attempts (students themselves or close friends); drug addiction; political violence; students hijacked and/or held at gunpoint; chronic hunger; and suffering from HIV/Aids. 


\section{Working with traumatised students: observations from respondents}

Teachers were asked whether they have worked with students whom they were aware of having been exposed to serious trauma and, if so, what they learnt from the experience. Twenty-two teachers indicated that they have indeed worked with traumatised students: aspects which came to mind included single severe incidents as well as the accumulation of a traumatic influence over a period of time.

\section{Previously disadvantaged students and students from broken homes: problems affecting the poor and the rich}

Problems at home have the most pervasive influence, potentially affecting all aspects of students' lives. Teachers who have worked with previously disadvantaged students identified concentration difficulties (commonly noted and described by one respondent as erratic concentration affecting performance in a student who was known to have been affected by political violence), frequent breakdowns during performance and lower achievement levels as common signs. It was noted that the emotional nature of music lessons often leads to tears and breakdown. It is not uncommon for these children to be hungry and suffering from HIV/Aids. Previously disadvantaged students tended to be markedly reserved in their emotional expression and became noticeably more expressive as they discovered that music is a means whereby they could explore their inner selves as they grew to trust the teacherlearner relationship. However, it appeared that the stress of performance made them relive their own personal stress and trauma, and performances inevitably suffered. For some of these children, coming to the music centre every afternoon irrespective of whether they had lessons scheduled or not was a means of escaping from their hardship.

The importance of learners needing to feel safe, to belong and to have secure boundaries was highlighted by respondents. If these elements were absent, emotional expression became distant and depression was common. While previously disadvantaged students are likely to lack a feeling of safety or secure boundaries, especially if they come from broken homes or households affected by disease, privileged students are also affected by similar challenges and teachers noted high rates of dysfunctional homes. Traumas were often related to the breaking up of families. Severe inner tension was audible in the music of these learners. It was noted that problems could only be resolved when learners were able either to get away from the circumstances or cut their emotional connections with the problem. Over-ambitious parents were also a particularly destructive influence on their children, sometimes with devastating consequences.

\section{Adjustments teachers made in their teaching}

Four teachers noted that they had to treat students with great patience, sensitivity and understanding, and had to refrain from applying pressure to achieve. The importance of applying 'constructive patience', yet encouraging perseverance in order to achieve success, the latter being a healing process, was explained. The patience of the teacher was especially challenged when reactions were excessive, and anger and resentment were always near the surface. It was found to be especially challenging to teach students who were verbally and psychically abused. Their teachers reported making an effort to help learners to change engrained negative thinking patterns, to reframe their thinking and to cultivate positive thinking patterns. Tension interfered with technique, and teachers incorporated relaxation techniques into their teaching and tried to remove the pressure of exams and performances. Whilst empathy and listening with understanding are important, teachers stated that learners do not want to be pitied. As one teacher commented: 'Become as noble and caring as possible 
- learn how to become empathic and walk the extra mile with others - yet focus on staying on the right side of professionalism.'

\section{Learning problems}

Traumatised students were noted to have difficulty with learning the notes of and interpreting new pieces. They were reported as battling to maintain concentration; they have difficulty studying any work, and exhibit fluctuating mind-sets and are inclined to be emotionally very vulnerable. Drug addicts were particularly difficult to teach: the reason for the addiction first had to be identified. If this is achieved and the journey to recovery embarked on, some responded well to music teaching and were even rehabilitated. Mild to seriously traumatised students were unresponsive during lessons and the teacher had to be satisfied if the students could play the correct notes. These students tended not to pay attention to dynamics and expressive features of the music.

\section{Insights gained}

Teachers remarked that they had learnt that having knowledge of students' background helps with understanding them 'and where they come from'. It is important that teachers realise when students are failing to progress according to their ability. For some, music serves as an 'escape' from the pain and can have a 'redemptive influence'. However, teachers also found that some students wanted to stop music lessons when traumatic events were impacting on other areas of their lives. A singing teacher was of the opinion that since singing utilises such a personal instrument in the form of a person's own voice, singers are more prone to the effects of traumatic events than other performers are. Another wrote that if aggression is channelled into singing, this can put too much pressure on the vocal cords, causing damage.

The role of the teacher was noted to be even more important in the case of young children. One teacher noted that for young children 'music and teacher are indivisible. A sympathetic teacher helps as much to re-establish stability as the music does.' All music teachers need to be very aware of their students' feelings and any changes. 'More than any other teachers the music teacher has a close relationship to the student. We may often be first to see signs.'

\section{General signs of trauma noted}

General signs indicating to teachers that students were suffering from the effects of trauma were consistent with those referred to in the literature on trauma, mostly centring on motivation, under-achievement and inadequate preparation, low self-esteem, mood swings or depression, loss of confidence, fearfulness, fatigue, tension, loss of breathing control in singers and wind players, change of appearance, and emotional as well as social withdrawal. Introversion, anxiety and sometimes anger lead to relational difficulties and changes in socialisation. The fact that traumatised learners experience a lot of stress was emphasised, and this was linked to physical difficulties such as tense body posture inhibiting movement at the instrument as well as emotional problems such as feelings of insecurity and worthlessness which affect motivation and performance. Trauma was noted to have caused 'extreme tension interfering with technique'. Effects could be so overwhelming that learners became unable to function. Such learners were noted to have searched for therapeutic or psychiatric intervention over extensive periods of time.

Decreased attention span and concentration deficits, often leading to inaccurate playing, were the most frequently identified signs. Concentration deficits were suspected as a cause of frequent memory lapses in these students. A case is made elsewhere for the role dissociation has to play as an aetiological factor in such occurrences of memory lapses in traumatised 
students (see Swart, Van Niekerk and Hartman 2010). Dissociation was not raised as an issue by these teachers, since a background in psychology is needed to make these links. Concentration problems and memory lapses were closely followed by suppression of emotions and expression of anger in music (identified both in instrumentalists as well as singers). Marked variations between learners were noted: while some struggled with interpretation, others found the performance of music therapeutic. Reactions ranged from complete withdrawal to using the instrument as an emotional outlet. Expression of emotion and memory for music are areas greatly affected and especially audible in the musical result, since they are so integral to the study and performance of music. It was observed that music could be an outlet for students, since it does not require that feelings be verbalised but provides a beneficial avenue for students 'to express themselves in an alternative way'. This is consistent with the findings of McClary (2002), Molnar-Szakacs and Overy (2006), Montello (2002), Peretz and Hebert (1995) and Scaer (2005), which will be discussed under the section on treatment possibilities.

\section{Referrals and recovery}

Only seven teachers indicated that they have ever referred students to appropriate healthcare services. Some teachers indicated that they did indeed speak to class teachers or remedial teachers of these students and/or to the headmaster or headmistress of the school, and that these individuals took the prescribed steps. One teacher remarked that, although one can sometimes easily identify problems, it can be challenging to find solutions since 'the pupil may not want you to speak to anyone about it'.

Teachers were asked about their perceptions of change and recovery in students whom they knew were receiving treatment (not necessarily referred by themselves). Many teachers alluded to the fact that, while there are great individual variations, recovery can be a lengthy process - lasting even years - before recovery is perceived in the lessons and performances.

- One teacher remarked that the symptoms are at their worst shortly after the onset of treatment, almost as if the student is reliving the trauma. Only afterwards does the healing process become evident and the symptoms diminish and sometimes recede completely.

- Yet another teacher remarked that, although signs diminished, they recurred occasionally.

- Symptoms never went away completely (in between two to four years), but treatment facilitated visible improvement. This was described by another teacher as students 'never fully regaining lost ground'.

- Expression eventually deepened only in cases where the situation was resolved. Psychosomatic symptoms were prevalent.

- Treatment helped students to gain control over emotions such as anger, grief and aggression. This was achieved in conjunction with the return of physical and psychic strength.

- Complete recovery was only attained in cases where the student was treated by 'an experienced specialist in that particular field'. In these cases, communication of emotion became more secure, frequency of memory lapses declined, focus and dedication improved, restlessness ceased and depressive symptoms diminished. Some of these students even considered music as a future career. 
- Emotions are often suppressed and, after healing, the playing again becomes more sensitive.

- It is important that students themselves should take control and find ways to handle the situation when 'triggers' appear.

- Performance and self-confidence improved and signs diminished.

Teachers working with students from previously disadvantaged communities stated that they and their colleagues often adopt the role of counsellors, since the students do not have the financial means to receive counselling. Teachers 'might not have the means to change their situations at home, etcetera, but at least we try to give the necessary comfort, support and love'.

\section{Advice of healthcare professionals to teachers}

Healthcare professionals warned against some common mistakes that teachers make when dealing with traumatised students. Their responses as anonymous research participants are exclusively based on their own experiences in treating clients who were musicians or music students, and are not related to the input received from the teachers. The most prevalent responses by the teachers were scolding, reprimanding, comments or criticisms aimed at reactive behaviour from the student that is a result of trauma (but the teacher perhaps does not realise this) and not related to the abilities of the student. Other responses on common mistakes include:

- Trying to handle this themselves;

- Not always realising that any behaviour that is different to the known profile could be a warning sign;

- Placing too much pressure on a student or increasing the workload so as to improve performance when progress was perceived as deteriorating could be detrimental (from two respondents);

- Insufficient understanding on the part of the teacher;

- Re-inflicting the damage by insensitive criticism or derogatory comments;

- Inappropriate probing;

- Labelling performers as people who should be able to overcome extra emotional stress (the old saying that 'the show must go on');

- Not believing students, telling them 'it is not so bad' or labelling them as troublesome;

- When the teacher misinterprets a disability as a lack of concentration or poor practice;

- Anything that causes anxiety in students and makes them feel unsafe to express their feelings and emotions.

Points of advice from HP's include:

- Teachers should be aware that the possibility exists that symptoms may be triggered in repeatedly traumatised musicians while they practise, preventing them from continuing their careers.

- A forensic psychologist emphasized the importance of not questioning the person about the traumatic event as this can lead to 'contamination of evidence' and adversely influence the relationship between teacher and student/performer. 
- It was suggested that a teacher who suspects abuse refer the student for assessment under the guise of 'assistance to reach his/her full potential'. In such a situation, any suspicions harboured by the teacher should be shared with the therapist only.

- A psychologist cautioned teachers to respect the boundaries of the student musicians and to be prepared to change the manner of teaching, perhaps on the advice of a trauma specialist.

- The importance of appropriate referrals was repeatedly emphasized.

\section{Responsibilities of music teachers regarding witnessing and referring}

\section{How and when to intervene}

There are times when intervention is necessary. Music teachers may sometimes find themselves to be in the best position to take action, especially since they often work with students on a one-on-one basis and might be told things which other teachers are less likely to hear. They should be equipped with transdisciplinary knowledge. Teachers' responsibility and influence extends to their immediate reactions to such news, or 'compassionate witnessing' as Weingarten $(2003,163)$ refers to this, but most importantly to appropriate referrals to trained professionals. An appreciation and understanding of the uniqueness of each student and of different students' and individuals' reactions to trauma are prerequisites to even begin to act in an appropriate manner (Swart 2010, 100).

Welbel's (2009) explanation that ultimately any relationship between human beings can have therapeutic components is relevant, given the previous discussions on the capacity of the environment and interaction with significant others to 'reshape' students' brains. She explains that teachers actually perform music therapy just by being, relating to their students, hearing and experiencing. However, as previously stated and without ever underestimating the importance of their influence on their students, teachers should know that they are not therapists and cannot act in that capacity.

Knowing the signs of possible trauma can help educators to act in the best interests of their students, to refer them in a timely way and to maintain the appropriate confidentiality. It is also important that any person in a teaching capacity is aware that there are clear linkages between childhood trauma and many psychiatric disorders. Educators should be familiar with their legal responsibilities regarding the reporting of child abuse.

Legal responsibilities, ethical considerations and the advice of healthcare professionals

The Children's Amendment Act s110 of 2007 states (Vetten 2012):

'Any teacher, medical practitioner, psychologist ... who on personal observation concludes that a child has been sexually abused, deliberately neglected or abused in a manner causing physical injury must report that conclusion to the provincial department of social development, a designated child protection organisation, police official or clerk of the children's court.'

In the article 'Reporting child abuse or ill-treatment' on the website of the South African Government Services (2008), Section 42 of the Child Care Act, 1983, such responsibility is stated more generally as teachers and medical practitioners being 'obliged to report any suspicions of child abuse or ill treatment'. According to De Wet and Oosthuizen (2001, 166167 ), educators who are negligent about reporting child abuse can be convicted for a criminal offence and also possibly held liable for civil remedy. De Wet and Oosthuizen (2001, 169- 
170) note that teachers often do not fulfil their duties in cases where they become aware of child abuse.

In cases of suspected domestic violence, abuse or incest, particular care should be taken not to jeopardise the victim through ill-considered disclosure to third parties - particularly keeping in mind possible retaliation by the perpetrator.

\section{Psychopathology outcomes}

It was noted above that trauma could lead to brain changes, developmental disorders and psychopathology. Luxenberg, Spinazzola and Van der Kolk (2001) identify the developmental level at which the trauma occurs and whether it occurs in the context of an important relationship in the victim's life as critical elements in determining psychopathological outcomes. Scaer (2005) states that complex trauma is associated with PTSD victims who were subjected to many episodes of traumatic stress particularly in childhood. Van der Kolk (1996) states that if the psychopathology of these patients is understood, it becomes possible to understand much of their symptomatology as caused by adaptations that were necessary at the developmental level at which the trauma occurred in order to survive the experiences.

\section{Differences of responses among teachers who indicated that they have experienced trauma themselves and those who have not}

An optional section in the research questionnaire invited teachers to write self-reports on traumas they had experienced themselves. Out of 27 teachers who responded to the questionnaire 20 confirmed that they had indeed personally experienced trauma, eight of whom mentioned having received professional treatment. Noteworthy (seeming) discrepancies were observed in the responses, particularly in the area where three teachers reported that they had never given any consideration to the influence of trauma on their students' progress and music-making, even though giving detailed self-reports of traumas personally experienced.

Ways in which the personal experiences of teachers relate to their professional evaluation of the influence of trauma on their students seem to suggest that some who reported that they had been traumatised and had not received treatment were unlikely to notice the possibility that trauma could be affecting their students. Swanepoel (2008) observed that there may be a tendency for musicians who have not dealt with their own trauma to feel alone and be less capable of recognising if and when others are also affected. On the other hand, the mere act of 'dealing' with past trauma possibly opens a person's eyes to the fact that many others could also be affected. This just serves to illustrate how, just as music itself is a dynamic and changing form of communication, so perception is a dynamic and changing form of observation.

\section{Empowering students through unlearning helplessness and fear}

Knowledge of the immobility response and learned helplessness can aid teachers in developing the necessary understanding to help re-instil their traumatised students' sense of 
control and mastery. Jensen (1998, 58-59) draws attention to the potentially debilitating effects of learned helplessness. Many repetitions of showing learners that they have the ability to exercise control over their circumstances and encouraging them to reengage in choicemaking are required to reverse the effects that biological rewiring of the brain had on subjects who perceived themselves as helpless during a traumatic situation (Jensen 1998, 58-59).

An understanding of how trauma can influence the psychological aspects of music performance, amplify stage fright, lead to concentration problems and even cause memory lapses is important to enable teachers to assist all their students - and not only the more resilient or 'lucky' ones - to reach their full potential (Swart 2010; Swart, Van Niekerk and Hartman 2010). Adequate knowledge of examples of how trauma influenced other musicians, particularly famous musicians, can help equip teachers to highlight learners' potential for growth. Such examples of identification with others could assist students to remain motivated even in the face of adverse circumstances, to evaluate their responses to trauma and explore alternative responses, enabling them to regain control over their lives and their choices. However, a prerequisite for such growth is that teachers begin by questioning their own metanarratives. Hlynka and Yeaman $(1992,4)$ state that it is important to support one's 'way of knowing' by operating from a mode of criticism yet not evaluation, and thereby recognising dysfunctions as well as functions. Only by not judging and not evaluating can dysfunctional as well as functional responses to trauma be identified.

\section{Treatment possibilities}

\section{Principles of potentially successful treatment strategies}

The focus in this article is on educational solutions to trauma, but a few core principles behind effective intervention have not yet been covered. In consulting the available literature on the handling of trauma sequelae and through the feedback to the research questionnaires, various treatment modalities emerged. However, a discussion of all these models is beyond the scope of this article and the reader is referred to Swart's (2010) original study for further information. The pre-eminent goal of all treatment should be to enable the affected learner to return to an optimal level of functioning in his or her daily life and so effect growth.

At the moment of imminent death, 'animals shake, sweat, and breathe it all out' (Scaer 2005, 285). Humans do not deal with trauma in the same way as animals, and problems develop because the emotional response to the trauma is not allowed to be completed. Levine (1997, 100-101) blames this on the neo-cortex, overriding the instinctual responses, which had the original function of completing this cycle.

Modern trauma-based psychotherapy works on the principle of synthesis and integration of traumatic material (Huopainen 2002, 97-98). Van der Kolk (1994, 12) maintains that returning to an optimally functioning, fully integrated state entails locating the traumatic experience in time, separating it from the reality of the present moment as well as the perception of potential future events in order to return to living fully in the present. In all the stages of psychotherapeutic intervention, including the referral and diagnostic stages, care should be taken not to re-traumatise an individual.

Treating trauma-related anger could involve various methods of restorative justice, an example of which is face-to-face meetings among the various parties connected to a particular 
violation (Winkel 2007, 27). This is the principle upon which the Truth and Reconciliation Commission, a restorative justice body assembled after the abolition of apartheid in South Africa and chaired by Archbishop Desmond Tutu, was constituted.

\section{Neurotransmitters and neural circuits}

The contribution of pharmacological intervention in the treatment of trauma symptoms can be of value in treatment under the supervision of a psychiatrist and used in conjunction with psychotherapy (Bremner 2002, 249-250; Van der Kolk 1994, 12). Medication works by modulating the neural feedback system. Levine $(2005,9)$ confirms that medication can at times be helpful, but also cautions that it is insufficient in itself.

The possible beneficial effects of natural supplements that enhance optimal brain function should also be considered (see Sahley 2009, 1; Holford 2007; Neurogenesis n.d.). The benefits of natural supplementation are that they assist the body's own capacity for self-healing and restoring homeostasis. If used as prescribed, this is a reasonably safe alternative to traditional pharmacological intervention, provided that pathological processes have not progressed beyond a critical point.

While pharmacological treatment places the emphasis on neurotransmitters and the balance and amounts thereof in different parts of the brain, Le Doux (2002, 261-2, 280, 294) argues that perhaps neural circuitry plays a greater role in brain pathology, including PTSD and depression, than neurotransmitters per se. This supports the argument in this article that placing control within the domain of the so-called victim opens possibilities for changing pathology by favourable environmental influences, increased control and command of the thinking processes.

\section{Traditional psychotherapeutic intervention strategies}

Blenkiron (2005) explains that Cognitive-Behavioural Therapy (CBT) deals with problems in the present and that there is a strong reliance on the way people think about problems as this directly affects their behaviour as well as how they feel physically and emotionally. CBT can be effective in the treatment of PTSD and its use with patients diagnosed with ASD can greatly reduce the chances that PTSD will develop subsequently (see e.g. Kornør, Winje, Ekeberg, Weisæth, Kirkehei, Johansen \& Steiro 2008).

Hypnosis can be used to alter the meaning of a traumatic event by reducing the perception of threat and also addressing somatic symptoms. Amendolia $(1998,1)$ describes hypnosis as structured dissociation and states that the goal of Ericksonian hypnotherapy is to recontextualise the memory as well as the effect of fear and physiological hyperarousal.

\section{Utilising eye movements and somatic experiencing}

Eye Movement Desensitization and Reprocessing (EMDR), originally developed by Francine Shapiro, is an information-processing therapy that uses fast lateral movements similar to those encountered in Rapid Eye Movement (REM) sleep (EMDR Institute 2004). Brenner (2004, 253-4) writes that inter-hemispheric stimulation is responsible for its integrative effect. While EMDR utilises REM, EMI uses Smooth Pursuit Eye Movements (SPEM) in multiple directions (Beaulieu n.d., 8), guided by slower hand movements. This 
technique helps the client's brain to access fragments of memory and form linkages between traumatic memories and more adaptive information (Beaulieu 2003, 69-113).

Trauma researcher Peter Levine developed the therapeutic modality Somatic Experiencing (SE) specifically for trauma intervention (Levine 2010, 74-95). During this process a therapist guides trauma survivors through renegotiation and transformation of traumatic experience through accessing sensations and thoughts through the felt sense, letting them peak and resolving them through allowing them to take their natural course (Levine 1997, 128). This is done through a series of nine well-defined but intertwined and interdependent steps. Levine states that the first three steps, namely the establishment of a safe environment, exploration and acceptance of sensation, and the use of the innate power of rhythm in establishing 'pendulation' and containment, must follow sequentially, while the remaining six steps can be accessed independently and in any order afterwards. They include using titration of survival-based arousal to recreate stability, resilience and organisation; providing corrective experience by substituting passive helplessness with active empowered defensive responses; separation of conditioned fear and helplessness from the immobility response; resolution of hyperarousal through the discharge of survival energy; restoration of 'dynamic equilibrium' through engaging self-regulation; and orienting the patient to the present, regrounding the patient and facilitating social engagement.

The success of this model lies in addressing the thwarted instinctual responses originating in the limbic system of the brain, integrating sensation, movement and cognition, and resolving bodily dissociation. In the light of this, it can be understood why modalities involving movement which are not necessarily designed as trauma therapy have been reported to show considerable healing properties. These include Dalcroze Eurhythmics and drumming (see Swart 2010). Although other avenues can provide benefits to traumatised students, it stands to reason that a systematic approach such as that of Levine will yield the greatest results.

\section{Ways in which music and art can facilitate healing}

McClary $(2007,156,259)$ focuses on the physicality and kinaesthetic aspects of making music as an avenue for releasing blocked feelings and accessing repressed memories as well as the healing nature of musically induced vibrations. According to Tooley (2007), given that all matter vibrates to a precise frequency, it is possible to restore balance by means of resonant vibration. Frawley (1997, 227) states: 'Sound, as the most primary sensory potential, generates the strongest emotions.' Musical direction entails degrees of tension and release which also underlies the experience of emotion and gives music its ability to contain, express and communicate emotions (i.e. Rose 1993, 509-510). Sutton (2002, 32-25) expresses the view that, since trauma disturbs the sense of bodily connectedness and music is a means of experiencing oneself in time, music therapy can be useful because of its qualities of 'musical embodiment'.

The section on the nature of the music teaching relationship touched on the role of music in establishing intra-psychic balance. Jung $(1973,542)$ wrote that music expresses the movement of feelings and emotional values that cling to unconscious processes and through this transforms the motifs of the collective unconscious. He was also of the opinion that music reaches deep archetypal material and should therefore form an essential part of every psychological intervention (Tilly 1997, 275).

Montello $(2002,124)$ states that music bypasses cortical functioning, enabling it to enter emotional centres of the brain directly before being processed by the conscious mind. 
McClary $(2007,159)$ explains that music's ability to bypass defences and provide a direct pathway to emotional and unconscious material is because music can act as symbolic representation for otherwise inexpressible experience. If a piece of music or art could be constructed (or reconstructed in the case of performance of compositions by others) into a realistic symbolic representation of traumatic events, it becomes possible to change the meaning of the event or events for the survival brain (Scaer 2005, 268). This is extremely helpful in the case of victims of early childhood trauma since, according to Scaer, their somatic memories of traumatic events are carried in their procedural memory and hence less accessible through verbal expression. Peretz and Hebert $(1995,128)$ illustrate by means of a case discussion of two brain-damaged patients that the processing avenues of music and language are not the same. In view of this, it can be argued that music may provide an avenue to the brain that cannot be accessed through traditional talk therapy.

Another application of how the input-processing pathways of the brain operate is posited by Rizzolatti and Craighero (2004). Their work centres on the human mirror neuron system, a system thought to enable the shared representation between sender and receiver necessary for any type of communication, including musical communication. Molnar-Szakacs and Overy (2006, 238) applied their work to music processing. They explain that the human mirror neuron system enables a person to understand the meaning of a communicative signal by stimulating a representation of that signal in the brain of the person perceiving the message. They $(2006,236-8)$ explained that this same mirror neuron system is responsible for our ability to understand the intentions behind the actions of others, to feel empathy, and to learn from the experience of others through action observation and imitation. According to them, imitative speech therapy techniques based on singing such as Melodic Intonation Therapy (MIT) work, because their imitative elements lead to the recruitment and co-activation of brain regions involved in the perceptive and productive aspects of music and language through the direct transfer of sensory information to a motor plan. Molnar-Szakacs and Overy $(2006,139)$ contend that music perception, cognition and emotion are linked via experiential and not representational mechanisms through the human mirror neuron system. Their research thus holds the promise of a better understanding of the neural basis of the interlinking of music and trauma, as well as offering possibilities for the healing of trauma through enabling a more precise understanding of how the brain constructs meaning and how different neuronal systems communicate with each other.

In conclusion, the explanations above again emphasise the importance of Levine's (2010, 249) statement, quoted earlier, that to know ourselves is to know our brains and vice versa. The article had also shown that to change our brains we need to change our actions, relations and environments and vice versa. The above arguments underscore the essence of this article which progresses from an understanding of how human beings relate according to Watkins's description of 'resonance', to music as an object relation, and finally to a neurological explanation for the mirroring required to teach, to learn and to develop as a human being.

\section{Future directions}

\section{Equipping teachers}

There are only two ways of increasing teachers' and students' awareness of trauma: personal experience (whether that of self or witnessing the effects on others) or education. Research should be done and action taken to determine how educational psychology teaching modules intended to educate teachers on manifestations of trauma and appropriate interventions could 
be incorporated into the music curricula at tertiary institutions in South Africa. The aim should be to produce a holistic educational outcome, equipping teachers to recognise general signs of trauma, including those connected to the instrument or voice, and familiarising them with the general manifestations of Acute Stress Disorder (ASD) and Post-Traumatic Stress Disorder (PTSD) symptoms. Teachers should be trained to make referrals in an appropriate manner and be cognisant of their legal responsibilities.

Short training and enrichment courses offered by institutions such as Unisa (University of South Africa) and ABRSM (Associated Board of the Royal Schools of Music) are an ideal platform where concise guidelines could be distributed to teachers who have already graduated or who do not have tertiary music training to make them aware of the main aspects related to the matter (Swart 2010, 202).

Providing good support structures for students in schools and reducing the risk of secondary traumatisation to professionals

Time limitations, financial restrictions and other problems challenge the ability of educational institutions in South Africa and elsewhere to provide safe boundary structures in cases where these may have been lacking in the immediate environment in which children live and grow up. However, if care is taken to make the circumstances within educational systems as safe and nurturing for the learners as possible, including providing reliable professional counselling services and equipping teachers with the necessary skills to deal appropriately with challenging situations, this can go a long way towards helping to diminish the adverse effects of a fractured and troubled society.

Exposure to secondary traumatisation, however, can take its toll on the health of teachers, HPs and researchers in the field of trauma. It is recommended that transdisciplinary collaboration be sought and explored in order to find and implement effective ways of reducing the risk to those investing their energy and resources in helping others.

\section{Collaboration between different disciplines}

The study of the impact of trauma is a multidimensional pursuit and transdisciplinary involvement should be an important element in this. Not only must the intrapersonal effects of trauma be understood, but also its interpersonal manifestations and intergenerational transmission. In addition, significant breakthroughs were made in recent years regarding the biological and physiological changes evident in trauma victims. Such studies need replication and further refinement, which could be achieved through a transdisciplinary discourse.

If researchers, musicians and teachers hope to find truthful answers and reach sound conclusions, the first step is achieving sufficient awareness of the complexities of human existence and implementing measures that would provide opportunities for transdisciplinary collaboration and communication between professionals.

\section{References}

Amendolia, R. 1998. A Narrative Constructivist Perspective of Treatment of PTSD with Ericksonian Hypnosis and EMDR. The American Academy of Experts in Traumatic Stress. Retrieved 10 April 2008, from <www.aaets.org/article32.htm>. 
Ashworth, P. 2003. Chapter 2: The origins of qualitative psychology. Pp. 4-23, in: Smith, J.A. (ed.). Qualitative Psychology: A Practical Guide to Research Methods. London: SAGE.

Beaulieu, D. 2003. Eye Movement Integration Therapy: The Comprehensive Clinical Guide. Carmarthen: Crown House Publishing.

Beaulieu, D. n.d. Efficacy of Eye Movement Integration Therapy: A novel therapy for rapid, ecological integration of traumatic memories. Available at <http://www.psykosyntesforum.se/uploads/EMI-paper.pdf>. Accessed 20 July 2008.

Blenkiron, P. 2005. Cognitive Behavioural Therapy. Royal College of Psychiatrists. Retrieved 1 September 2009, from $<$ http://www.rcpsych.ac.uk/mentalhealthinformation/therapies/cognitivebehaviouralth erapy. aspx>.

Bremner, D. 2002. Does Stress Damage the Brain? Understanding Trauma-Related Disorders from a Mind-Body Perspective. New York, NY: W.W. Norton.

Brenner, I. 2004. Psychic Trauma: Dynamics, Symptoms, and Treatment. New York, NY: Jason Aronson.

Brice, M. 2004. Unfolding human potential: An exploration of the teaching of Eurythmics In the light of the theory of Multiple Intelligences of Howard Gardner and the SocioCognitive approach of Britt-Mari Barth. Genève: Edition Papillon.

Cloud, J. 2010. Why Your DNA Isn't Your Destiny. Time Magazine Health. Retrieved on 13 April 2012, from <http://www.time.com/time/magazine/article/0,9171,1952313,00.html>.

Corsini, R.J. 2002. The Dictionary of Psychology. New York, NY: Brunner-Routledge.

De Wet, A. \& Oosthuizen, I. J. 2001. The educator's duty to report learner abuse and neglect. Perspectives in Education, Vol. 19(4):163-171.

Di Franco, G. 1993. Chapter 9. Music therapy: A Methodological Approach in the Mental Health Field. Pp. 82-90 in: Heal, M. \& Wigram, T. (eds.). Music Therapy in Health and Education. London: Jessica Kingsley.

Eccleston, A., DeWitt, N., Gunter, C., Marte, B. \& Nath, D. 2007. Nature Insight: Epigenetics. Nature 447,395.

Elliott, D. J. 1995. Music Matters: A New Philosophy of Music Education. Oxford: Oxford University Press.

EMDR Institute. 2004. A Brief Description of EMDR. Available at $<$ http://www.emdr.com/index.htm>. Accessed 7 April 2008.

Frawley, D. 1997. Ayurveda and the Mind: The Healing of Consciousness. Wisconsin: Lotus.

Genetic Science Learning Center. 2012. Lick Your Rats. Learn.Genetics. Retrieved April 15 2012, from <http://learn.genetics.utah.edu/content/epigenetics/rats/>.

Hanser, S.B. 1999. The New Music Therapist's Handbook. Second Edition. Boston, MA: Berklee Press. 
Heart, M.Y.H.B. 2005. From Intergenerational Trauma to Intergenerational Healing. Wellbriety! White Bison's online magazine. Vol. 6(6). Colorado Springs, CO: White Bison.

Hlynka, D. \&Yeaman, R. J. 1992. Postmodern educational technology. ERIC Digest No. EDO-IR-92-5. Syracuse NY: ERIC Clearinghouse on Information Resources.

Holford, P. 2007. Optimum Nutrition for the Mind. Laguna Beach, CA: Basic Health Publications.

Holmgren, E. (ed.). 2008/9. Musical Perspectives: Perspectives and Research in Music Performance. Available at <http://www.musicalperspectives.com/Site/Welcome.html $>$. Accessed 2 May 2009.

Huopainen, H. 2002. Freud's view of hysteria in light of modern trauma research. The Scandinavian Psychoanalytic Review, Vol. 25: 92-107.

Jausovec, N., Jausovec, K. \& Gerlic, I. 2006. The influence of Mozart's music on brain activity in the process of learning. Clinical Neuropsychology 117 (12), 2703-2714.

Jensen, E. 1998. Teaching with the brain in mind. Virginia: ASCD.

Jung, C. G. 1973. Letters, Vol. I (1906-50), eds. G. Adler \& A. Jaffe (R.F.C. Hull, trans.) Princeton, NJ: Princeton University Press.

Klein, M. 1946. Notes on some schizoid mechanisms. Envy and gratitude and other works 1946-1963. Richmond: Hogarth Press and the Institute of Psycho-Analysis (published 1975).

Kornør, H., Winje, D., Ekeberg, Ø., Weisæth, L.. Kirkehei, I., Johansen, K. \& Steiro, A. 2008. Early trauma-focused cognitive-behavioural therapy to prevent chronic posttraumatic stress disorder and related symptoms: A systematic review and metaanalysis. BMC Psychiatry. Vol8:81.

Latham-Radocy, W.B., Radocy, R.E. \& Hodges, D.A. (eds.). 1996. Handbook of Music Psychology. Second Edition. San Antonio: Institute for Music Research Press.

Latham-Radocy W.B. \& Radocy, R.E. 1996. Chapter 3: Basic Physical and Psychoacoustical Processes. Pp. 69-82, in: Hodges, D.A. (eds.). Handbook of Music Psychology. Second Edition. San Antonio: Institute for Music Research Press.

LeDoux, J. 2002. Synaptic Self: How Our Brains Become Who We Are. London: Macmillan.

Lee, D. J. 2009. A Phenomenological Study on Music Therapists Treating Trauma Patients.MA Thesis. Drexel University.

Levine, P. A. 2010. In an Unspoken voice: How the Body Releases Trauma and Restores Goodness. Berkeley: North Atlantic Books.

Levine, P. A. 2005. Healing Trauma: A Pioneering Program to Restore the Wisdom of Your Body. Boulder: Sounds True.

Levine, P.A. (with A. Frederick). 1997. Waking the Tiger-Healing Trauma. Berkeley, CA: North Atlantic Books.

Levitin, D. 2006. This is Your Brain on Music: Understanding a Human Obsession. London: Atlantic Books. 
Luxenberg, T., Spinazzola, J. \& Van der Kolk, B.A. 2001. Complex Trauma and Disorders of Extreme Stress (DESNOS) Diagnosis, Part One: Assessment. Directions in Psychiatry home-study CME. Pp. 373-394. Long Island City, NY: The Hatherleigh Comp.

Mandela, N. R. 1994. Long Walk to Freedom: The Autobiography of Nelson Mandela. London: Little, Brown \& Co.

Marczyk, G., De Matteo, D. \& Festinger, D. 2005. Essentials of Research Design and Methodology. Hoboken, NJ: John Wiley \& Sons.

Marshman, A. T. 2003. The Power of Music: A Jungian Aesthetic. Music Therapy Perspectives, Vol. 21(1): 21-26.

Maviglia, M.A. 2006. Pol.it: The Italian on line psychiatric magazine. Historical Trauma and PTSD: The "Existential" versus the "Clinical". Available at <http://www.priory.com/ital/fromstates2e.htm>. Accessed 10 April 2009.

McClary, R. 2007. Healing the psyche through music, myth, and ritual. Psychology of Aesthetics, Creativity, and the Arts, Vol. 1(3) Aug: 155-159.

Miller, A. 1997. The Drama of the Gifted Child: The Search for the True Self. New York, NY: Basic Books.

Molnar-Szakacs, I. \& Overy, K. 2006. Music and mirror neurons: from motion to 'e'motion. Social Cognitive and Affective Neuroscience, December 1(3): 235-241.

Montello, L. 2002. Essential musical intelligence: Using music as your path to healing, creativity, and radiant wellness. Wheaton, IL: Quest Books.

Neurogenesis. n.d. Neurotransmitters Overview. Retrieved 23 April 2009, from <http:/www.neurogenesis.com/Neurotransmitters/neurotransmitters-overview.php>.

Nijenhuis, E.R.S., van der Hart, O. \& Steele, K. 2004. Trauma-related structural dissociation of the personality. David Baldwin's Trauma Information Pages. Available at <http://www.trauma-pages.com/a/nijenhuis-2004.php>. Accessed 9 August 2008.

Peretz, I. \& Hebert, S. 1995. Music processing after brain damage: The case of rhythm without melody. In Music and the mind machine: The psychophysiology and psychopathology of the sense of music. In Steinberg, R. (Ed.), Music and the Mind Machine, pp. 127-137. Berlin: Springer.

Rauscher, F.H., Shaw, G.L. \& Ky, C. N. 1993. Music and spatial task performance. Nature $365,611$.

Rizzolatti, G. \& Craighero, L. 2004. The mirror-neuron system. Annual Review of Neuroscience, Vol. 27 July: 169-192.

Robertson, I. 1999. Mind Sculpture: Your Brain's Untapped Potential. London: Bantam Books.

Rose, G.J. 1993. Affect: A Biological Basis of Art. Journal of American Academy of Psychoanalysis. Vol. 21:501-512.

Roth, S. \& Friedman, M.J. 1998. Childhood Trauma Remembered: A Report on the Current Scientific Knowledge Base and its Applications. The International Society for Traumatic Stress Studies. 
Sahley, B. J. 2009. Current Practice and Research. National Center for Crisis Management in collaboration with the American Academy of Experts in Traumatic Stress. Available at <http://www.nc-cm.org/fbiobilliesahley.htm>. Accessed 23 April 2009.

Scaer, R.C. 2005. The Trauma Spectrum: Hidden Wounds and Human Resiliency. London: W.W. Norton.

Schore, A. N. 2012. Traumatic Attachment and the Early Origins of PTSD. Retrieved 13April, from <http://www.continuingedcourses.net/active/courses/course061.php?Help>.

Segal, H. 1981. The work of Hanna Segal: A Kleinian approach to clinical practice, New York, NY: Jason Aronson.

Skar, P. 2002. The goal as process: Music and the search for the Self. The Journal of Analytical Psychology, Vol. 47(4) Oct: 629-638.

South African Government Services. 2008. Reporting Child Abuse or Ill-Treatment. Retrieved $30 \quad$ September 2008, from <http://www.services.gov.za/servicesforpeople/Parenting/Childabuse/reportingchildab useorilltreatment.asp $x$ ?Language $=$ en-ZA $>$.

Spiegel, D. 2008. Coming Apart: Trauma and the fragmentation of the self. The Dana Foundation. Available at $<$ http://www.dana.org/news/cerebrum/detail.aspx?id=11122>. Accessed 6 April 2008.

Stein, A. 2007. Music and trauma in Polanski's The pianist (2002). Psychoanalytic Inquiry, Vol. 27(4) Sept-Oct: 440-454.

St. Clair, M. 2000. Object Relations and Self Psychology: An Introduction (3 ${ }^{\text {rd }}$ edition). Belmont, CA: Brooks/Cole Counseling.

Sutton, J. P. (ed.). 2002. Music, Music, Therapy and Trauma: International Perspectives. London: Jessica Kingsley.

Swanepoel, A. 2008. Personal interview with Dr A Swanepoel, Doctor of Chinese Medicine in Pretoria, South Africa, on 29 September.

Swart, I. 2010. The Influence of Trauma on Musicians. Unpublished DMus Thesis. University of Pretoria.

Swart, Van Niekerk, \& Hartman. 2010. Trauma-related dissociation as a factor affecting musicians' memory for music: Some possible solutions. Australian Journal of music Education 2010(2), 117-134.

Tilly, M. 1977. The therapy of music. C.G. Jung Speaking: 273-5. Eds. W. McGuire \& R.F.C. Hull. Princeton, NJ: Princeton University Press.

Tooley, A.C. 2007. Vibrational Medicine. Available at <http://www.luminanti.com/vibration.html>. Accessed 1 May 2009.

Tutu, D. M. 2011. God is not a Christian: Speaking truth in times of crisis. London: Rider.

Van der Kolk, B.A. 1996. Chapter 12. Memory: Mechanisms and Processes. Pp. 279-302, in: Van Der Kolk, B.A., McFarlane, A. C. \&Weisaeth, L. (eds.). Traumatic Stress: 
The Effects of Overwhelming Experience on Mind, Body, and Society. New York, NY: Guilford Press.

Van der Kolk, B. A. 1994. The body keeps the score: Memory and the evolving psychobiology of post traumatic stress. Retrieved 14 April 2008, from <http://www.trauma-pages.com/vanderk4.htm>.

Van der Kolk, B. A. 1989. The Compulsion to Repeat the Trauma: Re-enactment, Revictimization, and Masochism. Psychiatric Clinics of North America, Vol 12 (2), 389411.

Van der Kolk, B.A. \& McFarlane, A. 1996. Chapter 1. The black hole of trauma. Pp. 3-23, in: Van Der Kolk, B.A., McFarlane, A. C. \&Weisaeth, L. (eds.). Traumatic Stress: The Effects of Overwhelming Experience on Mind, Body, and Society. New York, NY: Guilford Press.

Van der Kolk, B.A. \& Saporta, J. 1991. The biological response to psychic trauma: mechanisms and treatment of intrusion and numbing. Anxiety Research (U.K.), Vol. 4:199-212.

Vetten, L. 2012. Introduction to the Sexual Offences act, 2007. Lecture notes. Tshwaranang Legal Advocacy Centre.

Watkins, J. G. 2005. Over-Resonance, the Emaciation and Destruction of Judy's Self: Modifications to Ego State Theory. Journal of Trauma E Dissociation, Vol. 6(2): 1-9.

Weaver, I.C.G., Cervoni, N., Champagne, F.A., D'Alessio, A.C., Sharma, S., Seckl, J.R., Dymov, S., Szyf, M. \& Meaney, M. 2004. Epigenetic programming by maternal behavior. Nature Neuroscience, 7, 847-854.

Weeks, D. 2000. Emotional Health and the Musician. Piano pedagogy Forum, Vol. 4(2) May.

Weingarten, K. 2003. Common Shock: Witnessing Violence Every Day: How We Are Harmed, How We Can Heal. New York, NY: Penguin Group.

Welbel, J. 2009. Personal interview with Dr JolantaWelbel, Department Psychology of Music, Fryderyk Chopin University of Music, Warsaw, Poland on 10 September.

Williams, R. B. 1978. Music therapy: How it helps the child. Psychology of Music, 6(1), 5560.

Winkel, F. W. 2007. Post Traumatic anger: Missing Link in the Wheel of Misfortune. Nijmegen, NL: Wolf.

Yehuda, R., Schmeidler, J., Elkin, A., Houshmand, E., Siever, L., Binder-Brynes, K., Wainberg, M., Aferiot, D., Lehman, A., Guo, L. S. \& Yang, R. K. 1997. Phenomenology \& Psychobiology of the Intergenerational Response to trauma. Available at <http://www.trauma-pages.com/a/yehuda97.php>. Accessed 14 November 2008.

Zimmer, C. 2010. The Brain Switches That Can Turn Mental Illness on and Off. Discover Magazine. Retrieved on 14 April 2012, from $<$ http://discovermagazine.com/2010/jun/15-brain-switches-that-can-turn-mentalillness-on-off $>$. 